\title{
The use of clinical guidelines for referral of patients with lesions suspicious for oral cancer may ease early diagnosis and improve education of healthcare professionals
}

\author{
Juan Seoane 1, Cesar Corral-Lizana ${ }^{2}$, Antonio González-Mosquera ${ }^{1}$, Rocío Cerero ${ }^{2}$, Germán Esparza ${ }^{2}$, \\ Teresa Sanz-Cuesta ${ }^{3}$, Pablo Varela-Centelles ${ }^{1}$
}

\footnotetext{
${ }^{1}$ Stomatology Department. School of Medicine and Dentristry. University of Santiago de Compostela (Spain)

${ }^{2}$ Department of Oral Medicine. School of Dentistry. Complutense University. Madrid (Spain)

${ }^{3}$ Unidad de investigación. Agencia Laín Entralgo. Madrid (Spain)
}

Correspondence:

Cantón Grande n ${ }^{\circ}$, Apto. $1^{\circ}$,

15003 A Coruña,

Spain,

juanmanuel.seoane@usc.es

Received: 28/02/2010

Accepted: 08/12/2010

\author{
Seoane J, Corral-Lizana C, González-Mosquera A, Cerero R, Esparza G, \\ Sanz-Cuesta T, Varela-Centelles P. The use of clinical guidelines for re- \\ ferral of patients with lesions suspicious for oral cancer may ease early \\ diagnosis and improve education of healthcare professionals. Med Oral \\ Patol Oral Cir Bucal. 2011 Nov 1;16 (7):e864-9. \\ http://www.medicinaoral.com/medoralfree01/v16i7/medoralv16i7p864.pdf \\ Article Number: $16904 \quad$ http://www.medicinaoral.com/ \\ (C) Medicina Oral S. L. C.I.F. B 96689336 - pISSN 1698-4447 - eISSN: 1698-6946 \\ eMail: medicina@medicinaoral.com \\ Indexed in: \\ Science Citation Index Expanded \\ Science Citation Index Expa
Journal Citation Reports \\ Index Medicus, MEDLINE, PubMed \\ Scopus, Embase and Emcare \\ Indice Médico Español
}

\begin{abstract}
Early diagnosis and referral of oral cancer is essential. Successful implementation of clinical guidelines must include current practitioners and students.

Objective: To evaluate the diagnostic accuracy of students at oral cancer screening and to assess the effectiveness of clinical referral guidelines.

Study Design: Fifth year dental students were randomly allocated to either control $(n=19)$ or experimental groups $(\mathrm{n}=18)$. Both received the customary training in oral diagnosis. The experimental group underwent a 2 hour workshop where the guidelines for the referral of suspicious lesions were discussed. Three months later, a set of 51 clinical cases including benign, malignant, and precancerous conditions/lesions were used to assess the screening ability of each subject.

Results: All 37 students entered the study. Sensitivity (control group) ranged from $16.7 \%$ to $66.7 \%$; the experimental group scored from $16.7 \%$ to $83.3 \%$. Fifty percent of the experimental students reached sensitivity values $\geq 62.5 \%$ $(\mathrm{p}=0.01$ ). Diagnostic specificity (control group) spanned from $80 \%$ to $93.3 \%$ (median $=50 \%$ ); amongst experimental group it ranged from $82.2 \%$ to $97.8 \%$ (median=92.8\%); $(\mathrm{p}=0.003$ ). Concordance -control group- was $\mathrm{X}=82.5$ $(\mathrm{SD}=3.2)$, and $\mathrm{X}=88.2(\mathrm{SD}=4.3)$ for the experimental, $(\mathrm{p}>0.001)$. Cohen's kappa test was poor $(\mathrm{K}<0.40)$ for the controls and moderate for the experimental group. The experimental group referred more oral cancers urgently $(p=0.002)$ and left less unreferred cancers $(0.04)$. This group also referred more precancerous lesions/conditions urgently $(\mathrm{p}=0.02)$.

Conclusions: The implementation of a clinical referral guideline at undergraduate level has proved valuable, under experimental conditions, to significantly increase diagnostic abilities of the examiners and thus to improve screening for oral cancer.
\end{abstract}

Key words: Oral cancer, students, undergraduate, practice guideline. 


\section{Introduction}

Worldwide, oral cancer has one of the lowest survival rates and remains unaffected despite recent therapeutic advances (1). Early diagnosis and referral is a cornerstone to improve survival and to reduce diagnostic delay (2). Unfortunately, almost one half of the oral cancers are diagnosed at advanced stages (III or IV), with 5-year survival rates ranging from $20 \%$ to $50 \%$ depending on tumour site (3).

The limited value of oral cancer screening programmes for the general population justifies opportunistic screening during routine health check-ups (3). However, several authors have identified insufficient educational preparedness of medical and dental professionals to reduce the burden of oral cancer through effective cancer control strategies such as reducing tobacco consumption, suggesting healthier diet and lifestyles and, particularly, performing early detection through screening examinations and appropriate follow-up (4) . This educational gap has also been identified among graduating medical and dental students around the world $(5,6)$.

The introduction of guidelines for the referral of suspected cancer is an important step towards primary care practitioners identifying patients with oral malignancy and ensuring urgent specialist opinion (7) that has already been taken by some countries (8-10). However, successful implementation of clinical guidelines must include not only current practitioners but also students $(11,12)$, nevertheless -and to the best of our knowledge- no oral cancer undergraduate medical or dental curricula include this topic.
The aim of this study was to evaluate the level of diagnostic accuracy of fifth-year dental students as examiners for the screening of oral malignant lesions and to assess the effectiveness of the implementation of a clinical referral guideline for undergraduate dental students.

\section{Material and Methods}

We designed an experimental intervention study where 37 fifth year undergraduate dental students were randomly allocated to either control $(n=19)$ or experimental groups $(\mathrm{n}=18)$. Both groups had received the customary training in oral diagnosis: soft tissue diagnosis instruction is undertaken from a multidisciplinary approach through different years, and includes otorhinolaryngology, dermatology, oral and maxillofacial medicine and oral and maxillofacial surgery.

At the beginning of the study, the experimental group received a 2 hour seminar (workshop) supported by simulated clinical cases (image and clinical records), where the guidelines for the referral of suspected cancer were discussed. The clinical guideline employed in this study was the Clinical Guideline for Referral of Oral Cancer published by the Dental Council (Tables 1 and 2).

Three months later, a set of 51 clinical cases including 30 benign lesions, 6 malignant lesions and 15 precancerous conditions/lesions all previously pathologically diagnosed were used as a gold standard in order to assess the screening ability of each subject, both in the experimental and control groups.

The clinical cases consisted of clinical notes including

Table 1. Approach to oral cancer screening.

\begin{tabular}{|c|c|c|}
\hline $\begin{array}{l}\text { 1. Examination for early } \\
\text { diagnosis of oral cancer }\end{array}$ & \multicolumn{2}{|c|}{$\begin{array}{l}\text { Every patient must be explored for potential malignant and premalignant lesions each time a } \\
\text { dental check-up is performed. A particularly thorough examination is required on smokers, } \\
\text { heavy drinkers or on patients elder than } 40 \text {. }\end{array}$} \\
\hline \multirow{2}{*}{$\begin{array}{l}\text { 2. Referral scheme for oral } \\
\text { lesions suspicious for } \\
\text { malignancy }\end{array}$} & \multirow{2}{*}{$\begin{array}{l}\text { When a suspicious lesion is } \\
\text { detected, biopsy is the only } \\
\text { method to ascertain whether or } \\
\text { not it is malignant. The } \\
\text { clinician can opt for two } \\
\text { actions: }\end{array}$} & $\begin{array}{l}\text { - If the clinician feels qualified and confident, he/she can } \\
\text { perform the biopsy and refer the patient to a specialised } \\
\text { centre in case of malignancy. }\end{array}$ \\
\hline & & - Refer the patient directly to a specialised centre. \\
\hline \multirow{5}{*}{$\begin{array}{l}\text { 3. Information to include } \\
\text { in the referral letter }\end{array}$} & \multirow{5}{*}{$\begin{array}{l}\text { It is essential for the } \\
\text { consultant to know certain } \\
\text { data about the patient, the } \\
\text { lesion and the clinical } \\
\text { diagnosis in order to establish } \\
\text { priorities within the waiting } \\
\text { list. Relevant data are: }\end{array}$} & $\begin{array}{l}\text { Patient data: address, age, telephone number in order to } \\
\text { contact the patient. }\end{array}$ \\
\hline & & $\begin{array}{l}\text { Brief medical history: relevant systemic disorders, } \\
\text { medication he/she is taking and patient's physician and } \\
\text { dentist telephone numbers. }\end{array}$ \\
\hline & & $\begin{array}{l}\text { Relevant facts of patient's social history, including alcohol } \\
\text { and tobacco consumption. }\end{array}$ \\
\hline & & $\begin{array}{l}\text { A detailed description of the lesion: data of appearance, site, } \\
\text { size, colour and consistency. }\end{array}$ \\
\hline & & $\begin{array}{l}\text { Clinical diagnosis in order to allow categorization of the } \\
\text { referral urgency. }\end{array}$ \\
\hline
\end{tabular}


Table 2. Dental Council referral scheme for lesions suspicious for oral cancer.

\begin{tabular}{|c|c|c|}
\hline Referral type & Example & Refer to \\
\hline Preferential & $\begin{array}{l}\text { - Ulceration that persists more than } 14 \text { days after removing } \\
\text { its hypothetical cause. } \\
\text { - White, red or white-reddish lesions that cannot be scrapped off. } \\
\text { - Evident lump } \\
\text { - Localised pigmented lesion. } \\
\text { - Any oral lesion with suspicious features: rapid growth, } \\
\text { infiltration, induration, fixation. } \\
\text { - Non-visible but palpable intraoral lumps. } \\
\text { - Non-explained orofacial pain that persists longer than } 4 \text { weeks. } \\
\text { - Unexplained recent neck lump. } \\
\text { - Unexplainde dysphagia lasting longer than } 3 \text { weeks. } \\
\text { - Unexplained dental mobility lasting longer than } 3 \text { weeks } \\
\text { that cannot be related to trauma or periodontal disease. } \\
\text { - Unexplained osseous lesion. } \\
\text { - Decrease of orofacial sensitivity and paralysis of unknown } \\
\text { origin. }\end{array}$ & $\begin{array}{l}\text { Oral and Maxillofacial surgery } \\
\text { Service, Stomatology Service or any } \\
\text { other specilised unit. } \\
\text { Referral paths should be agreed in } \\
\text { advance with the local specialised } \\
\text { units. }\end{array}$ \\
\hline Normal & - Any other disorder requiring medico-surgical treatment. & \\
\hline
\end{tabular}

age and gender of the patients, location, clinical symptoms, time of evolution and performance of the lesion as well as data related to palpation plus an image of the lesion and surrounding tissues. The image, obtained by means of an Olympus E-510 (Olympus Imaging Corporation, Hamburg, Germany), was project as a slide for 2 minutes.

The questionnaire included an anonymous answer sheet where the students had to choose on three possible answers: benign lesion, malignant lesion, or precancerous lesion/condition. Data for each parameter were determined on two-category bases (oral cancer - other lesions). Students also had to decide on the convenience of patient referral (no referral, standard referral, urgent referral).

The results were entered into a database (dBase IV) and analysed by means of a statistical package (SPSS/ $\mathrm{PC}+$ ). Sensitivity, specificity, wrong classifications and percentage of total agreement (concordance) for each student were obtained, as well as statistical indices for position and spread. The calculation of the Kappa coefficient of agreement for each student relied on the three responses, and used the Cohen's Kappa test with three ranges of values (excellent $(\mathrm{K}>0.75)$, moderate $(0.40 \leq \mathrm{K} \leq 0.75)$ and poor $(\mathrm{K}<0.40)$. The Mann-Whitney $\mathrm{U}$ non-parametric test assessed the comparisons between groups. The significance level chosen for all tests was $5 \%$.

\section{Results}

The participation rate was $100 \%(n=37)$ of fifth year undergraduate students. Results are summarised in (Tables 3 and 4).

Sensitivity in the control group ranged from $16.7 \%$ to $66.7 \%$. The experimental group scored within a range from $16.7 \%$ to $83.3 \%$. Fifty percent of the students in the experimental group reached sensitivity values equal or higher than $62.5 \%$ which was significantly different from the mean value observed in the control group $(\mathrm{p}=0.01)$.

Diagnostic specificity in the control group spanned from $80 \%$ to $93.3 \%$ with a median of $50 \%$. The experimental value registered a minimum value of 
Table 3. Results of the intervention (cancer vs. precancer + benign).

\begin{tabular}{|l|c|c|c|c|c|c|c|}
\hline & \multicolumn{3}{|c|}{ With Guideline } & \multicolumn{2}{c|}{ Without Guideline } & \multirow{2}{*}{$\begin{array}{c}\text { Signification } \\
\text { level }\end{array}$} \\
\hline & Media & SD & N & Media & SD & N & \\
\hline Sensitivity & 58.34 & 14.00 & 18 & 44.73 & 15.77 & 19 & 0.01 \\
\hline Specificity & 92.27 & 4.82 & 18 & 87.63 & 4.23 & 19 & 0.003 \\
\hline Wrong classifications & 11.8 & 4.39 & 18 & 17.49 & 3.24 & 19 & 0.001 \\
\hline Kappa & 0.484 & 0.157 & 18 & 0.273 & 0.109 & 19 & $<0.001$ \\
\hline
\end{tabular}

(a) Mann-Whitney Test; SD: Standard deviation.

Table 4. Results of the intervention (type of lesion and referral priority).

\begin{tabular}{|l|c|c|c|c|c|c|c|}
\hline & \multicolumn{3}{|c|}{ With Guideline } & \multicolumn{2}{c|}{ Without Guideline } & \\
\cline { 2 - 9 } & Media & SD & N & Media & SD & N & $\begin{array}{c}\text { Signification } \\
\text { level }\end{array}$ \\
\hline Benign lesions with urgent referral & 23.72 & 12.14 & 18 & 17.73 & 9.99 & 19 & 0.066 \\
\hline Precancerous lesions with urgent referral & 58.42 & 23.86 & 18 & 38.78 & 20.93 & 19 & 0.020 \\
\hline Cancerous lesions not referred & 4.17 & 9.04 & 18 & 14.04 & 13.89 & 19 & 0.049 \\
\hline Cancerous lesions with normal referral & 10.42 & 12.62 & 18 & 16.68 & 9.81 & 19 & 0.066 \\
\hline Cancerous lesions with urgent referral & 85.42 & 13.80 & 18 & 69.30 & 13.89 & 19 & 0.002 \\
\hline
\end{tabular}

(a) Mann-Whitney Test; SD: Standard deviation.

$82.2 \%$ and a maximum of $97.8 \%$ with a median of $92.8 \%$. The specificity in the diagnosis of oral cancer was significantly higher amongst the students that underwent the educational intervention $(p=0.003)$.

Overall diagnostic concordance for the control group was $(\mathrm{X}=82.5 \mathrm{SD}=3.2)$, whereas the total percentage of agreements in the experimental group was $X=88.2$ $(\mathrm{SD}=4.3)$, being this difference statistically significant ( $\mathrm{p}>0.001)$. Cohen's kappa test was poor $(\mathrm{K}<0.40)$ for the control group and moderate for the experimental one.

The proportion of oral cancers that were indicated for urgent referral by the students in the experimental group was significantly higher $(\mathrm{p}=0.002)$, and the number of oral cancers that received no indication for referral was superior in the control group $(p=0.04)$. The use of the referral guideline also lead to a significant increase in the urgent referral of precancerous lesions/conditons $(p=0.02)$. Furthermore, this increment of referrals did not reach signification for benign lesions (0.06).

\section{Discussion}

Oral cancer is a major health problem and its diagnosis at early stages is an educational objective and the basis for cancer prevention (12). It is the universities' duty to plan procedures for diagnostic assessment that are independent, valid and reliable besides permitting the achievement of the curriculum objectives. These procedures are particularly important when graduating medical and dental students are still deficient regarding certain risk factors, guidelines for oral screening, and head and neck examination techniques (6). Moreover, delays in referral of suspected oral cancer cases for treatment caused by the clinicians have been identified by several reports. Thus, the design of a simple, clear, fail-safe referral scheme may greatly diminish the length of the delay (12).

Previous reports have used survey-type questionnaires to evaluate physicians and dentists' ability to diagnose 
and make proper referral for treatment of oropharyngeal cancers (13). However, these investigations supply data on perceptions and knowledge on oral cancer but do not inform on how effective physicians and dentists are at screening and detecting those cancers. To test knowledge is surely important an important goal, but these questionnaires are incomplete tools for assessing competence at a professional task. On the other hand, the use of clinical cases (images and clinical records) has been widely utilised for evaluating and training screeners for oral cancer and precancer (14-16).

Concordance can be defined as the proportion of correctly classified subjects. It is generally accepted that a total percentage of agreement (concordance) higher than 80 percent is acceptable for systematic screening for oral cancer (16). This threshold has been achieved by both groups of students even though the experimental group displayed a significantly higher diagnostic agreement. However, adequate concordance values often hide other low values, specially the ones derived from sensitivity scores. The ability of the examiners to make a correct positive detection of oral cancer (sensitivity, Sn) shows a broad range worldwide: reported $\mathrm{Sn}$ scores varied from 0.4 to $0.9(17)$. The specificity $(\mathrm{Sp})$ ranged to 0.3 to 0.92 (17), low values scores for the screening of oral cancer would mean that patients with oral cancer may not be adequately referred for the decisive diagnosis and treatment.

The use of the clinical guideline for referral of patients seems to significantly increase the diagnostic specificity for oral cancer and also to reduce the possibility of not referring an oral cancer case, and thus increasing the diagnostic delay.

According to previous reports, students usually score higher values for specificity than for sensitivity (17). This phenomenon has also been described when the use of referral guidelines was studied in primary care settings. The "Two weeks wait" scheme was rolled out in December 2000 for Head and Neck cancer referrals in the United Kingdom (Department of Health, 2000). An audit of this initiative revealed a high proportion of non-malignancies were referred via the fast track system to the hospitals due to low sensitivity of visual detector guidelines (11). In our study, the use of a clinical practice guideline did not significantly increase the urgent referral of benign lesions.

Regarding to oral and pharyngeal cancers, medical and dental students should have demonstrated -prior to graduation- knowledge and skill to perform primary prevention (promoting a healthier lifestyle). Moreover, a worrying ignorance on oral changes associated to early forms of oral cancer (early diagnosissecondary prevention) particularly about leucoplastic, erythroplastic or leucoerythroplastic lesions amongst medical and dental students (18). The implementation of clinical guidelines for undergraduate students aimed at reinforcing these topics may increase diagnostic sensitivity and specificity when dealing with lesions suspicious for oral cancer.

The clinical practice guideline (CPG) for referral of oral cancer suspicious lesions has been elaborated by a panel of experts synthesising the best available scientific evidence. The objective of the implementation of CPGs is to increase knowledge, to change behaviours and attitudes in clinical practice and to improve the quality of the clinical care $(19,20)$. Clearly is essential that undergraduate and postgraduate medical and dental education should include the characteristics of a good referral guide in order to improve standards.

\section{Conclusion}

The implementation of a clinical referral guideline for patients with lesions suspicious for malignancy at undergraduate level has proved valuable, under experimental conditions, to significantly increase diagnostic abilities of the examiners and thus to improve screening for oral cancer. Undergraduate education seems to be an adequate setting for applying CPGs and would allow for identification of triggers and barriers related to the clinician and the environment.

\section{References}

References with links to Crossref - DOI

1. Warnakulasuriya S. Global epidemiology of oral and oropharyngeal cancer. Oral Oncol. 2009;45:309-16.

2. Holmes JD, Dierks EJ, Homer LD, Potter BE. Is detection of oral and oropharyngeal squamous cancer by a dental health care provider associated with a lower stage at diagnosis? J Oral Maxillofac Surg. 2003;61:285-91.

3. Kujan O, Glenny AM, Sloan P. Screening for oral cancer. Lancet. 2005;366:1265-6.

4. Patton LL, Ashe TE, Elter JR, Southerland JH, Strauss RP. Adequacy of training in oral cancer prevention and screening as self-assessed by physicians, nurse practitioners, and dental health professionals. Oral Surg Oral Med Oral Pathol Oral Radiol Endod. 2006;102:758-64.

5. Seoane J, González-Reforma N, Aguado A, Romero MA, VarelaCentelles PI. Assessment of dental students' diagnostic accuracy for oral cancer screening. J Dent Educ. 1997;61:437-9.

6. Reed SG, Duffy NG, Walters KC, Day TA. Oral cancer knowledge and experience: a survey of South Carolina medical students in 2002. J Cancer Educ. 2005;20:136-42.

7. Mohyuddin N, Langerman A, LeHew C, Kaste L, Pytynia K. Knowledge of head and

neck cancer among medical students at 2 Chicago universities. Arch Otolaryngol Head Neck Surg. 2008;134:1294-8.

8. Hodgson TA, Buchanan JA, Garg A, Ilyas SE, Porter SR. An audit of the UK national cancer referral guidelines for suspected oral mucosal malignancy. Br Dent J. 2006;201:643-7.

9. Navarro CM, Onofre MA, Sposto MR. Referral letters in oral medicine: an approach for the general dental practitioner. Int J Oral Maxillofac Surg. 2001;30:448-51.

10. Canto MT, Horowitz AM, Drury TF, Goodman HS. Maryland family physicians' knowledge, opinions and practices about oral cancer. Oral Oncol. 2002;38:416-24.

11. Singh $P$, Warnakulasuriya $S$. The two-week wait cancer initiative on oral cancer; the predictive value of urgent referrals to an oral medicine unit. Br Dent J. 2006;201:717-20. 
12. Higuchi KA, Cragg CE, Diem E, Molnar J, O’Donohue MS. Integrating clinical guidelines into nursing education. Int $\mathrm{J}$ Nurs Educ Scholarsh. 2006;3:12.

13. Joshi A, Doyle L, Worthington HV, Rood JP. Direct access day case oral surgery. Br Dent J. 2000;188:452-6.

14. Yellowitz JA, Horowitz AM, Drury TF, Goodman HS. Survey of U.S. dentists' knowledge and opinions about oral pharyngeal cancer. J Am Dent Assoc. 2000;131:653-61.

15. Seoane J, Warnakulasuriya S, Varela-Centelles P, Esparza G, Dios PD. Oral cancer: experiences and diagnostic abilities elicited by dentists in North-western Spain. Oral Dis. 2006;12:487-92.

16. Jullien JA, Zakrzewska JM, Downer MC, Speight PM. Attendance and compliance at an oral cancer screening programme in a general medical practice. Eur J Cancer B Oral Oncol. 1995;31B:202-6.

17. Speight PM, Palmer S, Moles DR, Downer MC, Smith DH, Henriksson $\mathrm{M}$, et al. The cost-effectiveness of screening for oral cancer in primary care. Health Technol Assess. 2006;10:1-144.

18. Carter LM, Ogden GR. Oral cancer awareness of undergraduate medical and dental students. BMC Med Educ. 2007;7:44.

19. Hutchinson A, McIntosh A, Cox S, Gilbert C. Towards efficient guidelines: how to monitor guideline use in primary care. Health Technol Assess. 2003;7:1-97.

20. Grimshaw JM, Thomas RE, MacLennan G, Fraser C, Ramsay CR, Vale L, et al. Effectiveness and efficiency of guideline dissemination and implementation strategies. Health Technol Assess. 2004;8:1-72. 